\title{
Lineal kinship organization in cross-specific perspective
}

\author{
Laura Fortunato \\ Institute of Cognitive and Evolutionary Anthropology \\ University of Oxford \\ 64 Banbury Road, Oxford OX2 6PN, UK \\ laura.fortunato@anthro.ox.ac.uk \\ +44(0)1865 284971 \\ Santa Fe Institute \\ 1399 Hyde Park Road \\ Santa Fe, NM 87501, USA
}

Published as: Fortunato, L. (2019). Lineal kinship organization in cross-specific perspective. Philosophical Transactions of the Royal Society B: Biological Sciences, 374(1780):20190005. http: //dx.doi.org/10.1098/rstb.2019.0005,

The article is part of the theme issue "The evolution of female-biased kinship in humans and other mammals". http://dx.doi.org/10.1098/rstb/374/1780. 


\section{Contents}

1 Introduction $\quad 4$

2 Kinship vs. descent $\quad 5$

3 Lineal kinship in cross-specific perspective $r$

4 Lineal kinship in cross-cultural perspective $\quad 12$

4.1 A cross-cultural example: the association between descent and residence . . . . . . 13

4.2 Reframing lineal kinship organization as lineal biases in kin investment . . . . . . . 19

5 Conclusion $\quad 21$

$\begin{array}{ll}\text { References } & 23\end{array}$ 


\begin{abstract}
I draw on insights from anthropology to outline a framework for the study of kinship systems that applies across animal species with biparental sexual reproduction. In particular, I define lineal kinship organization as a social system that emphasizes interactions among lineally related kin - that is, individuals related through females only, if the emphasis is towards matrilineal kin, and individuals related through males only, if the emphasis is towards patrilineal kin. In a given population, the emphasis may be expressed in one or more social domains, corresponding to pathways for the transmission of different resources across generations (e.g. the allocation of food, the transfer of access to the natal territory or household).

A lineal bias in any domain can be viewed as a bias in investment towards a particular set of kin - specifically, towards the offspring of daughters if the bias is matrilineal, and towards the offspring of sons if the bias is patrilineal. Effectively, investment is restricted to the offspring of the females in the population in one case, and to the offspring of the males in the other. This is distinct from a bias in investment towards daughters and towards sons, respectively.

Overall, I propose a shift in focus - from viewing matrilineal and patrilineal kinship as unitary phenomena, to consideration of the different aspects of the social system featuring a bias towards lineally related kin.
\end{abstract}

Keywords kinship systems, lineal kinship organization, matrilineal, patrilineal, descent, postmarital residence 


\section{Introduction}

In his now classic Kinship and marriage: an anthropological perspective, Fox (1983, p. 50) lamented that "anyone trying to understand the subject has to fight his way through half a dozen conflicting taxonomies each with its patchy, ad hoc terminology." Against this background, what follows may appear as a long-winded attempt to define "matriliny" and related concepts, and in particular to disentangle descent from other aspects of matrilineal kinship in humans. In some ways, perhaps, it is. Yet extensive sleuthing through anthropological sources, old and new, suggests that terminological clarity is the key to conceptual progress in this area. It is also a critical first step towards development of a cross-specific perspective, bridging the persistent divide between the study of human and non-human kinship systems.

Calls to clarify relevant terms and concepts have appeared periodically in the anthropological literature, as interest in matriliny waxed and waned over the course of a century, from the early 1860s through to the 1960s (e.g. Bachofen, 1861; Douglas, 1969; Schneider and Gough, 1961; see Parkin, 1997, chs. 11-12, and Peters, 1997, for historical overviews). The topic enjoyed a brief resurgence during the 1970s and early 1980s in the context of feminist analysis, which focused on understanding the roles of women at the intersection of gender construction and family organization (Peters, 1997). In a parallel development, at around the same time researchers interested in the evolution of human social behaviour turned to matriliny as a test case for the application of kin selection theory (e.g. Alexander, 1974, 1977; Flinn, 1981; Gaulin and Schlegel, 1980; Greene, 1978; Hartung, 1981, 1985; Kurland, 1979; see Gray and Wolfe, 1982, Hartung, 1982, and Wolfe and Gray, 1981, for critical discussion). Many of the insights that had been gained over a century of anthropological enquiry were lost in this context - including an understanding of what matriliny is, and what it is not.

Faced with multiple and ambiguous definitions, evolutionarily minded anthropologists have recently taken a pragmatic stance, replacing "matrilineal kinship" with biologically inspired labels,

such as "female-biased/based/centred kinship" (e.g. Mattison et al., 2019, and other articles in the theme issue). Underlying this trend is the belief that, if we move past seemingly trivial debates about terminology, we can turn to hypotheses, data, and analyses of ever-increasing sophistication. 
However, this approach simply sidesteps the issue, compounding conceptual blindspots that had been at least partly addressed in anthropology over the course of the twentieth century.

I aim to show that, perhaps counterintuitively, exposing the ambiguity in terminology goes a long way towards resolving the conceptual confusion. It then becomes possible to outline a framework for the study of kinship systems that applies across animal species with biparental sexual reproduction. Reasoning from first principles, I develop such a framework in the abstract, without reference to the social organization of specific human or non-human populations. This is a deliberate strategy, to avoid conflict with established interpretations of relevant patterns. I begin by providing explicit definitions of key terms and concepts (Section 2). Next, I derive the logical implications of the definitions in cross-specific perspective (Section 3). The insights that emerge are then applied in cross-cultural perspective (Section 4). In particular, I corroborate these insights by (i) examining the distribution of two relevant features of human social organization (Section 4.1), (ii) briefly summarizing related conclusions obtained through anthropological analysis in the twentieth century (Section 4.2), and (iii) reframing lineal kinship organization in terms of biases in investment towards specific sets of kin (Section 4.2). I conclude by outlining how this framework applies across species (Section 5). Readers interested exclusively in non-human social behaviour can skip Sections 2 and 4, focusing on Sections 3 and 5 instead.

\section{Kinship vs. descent}

Let's begin by drawing a distinction between the notions of kinship and descent, which is central to related discussions in anthropology. My aim here is two-fold: first, to explicitly define key terms and concepts, in order to address the confusion surrounding their use; second, to provide a minimal compendium, for reference, which reconciles the multitude of definitions found in the literature. Relevant terms and concepts are then applied in cross-specific perspective in Section 3.

Across human societies, kinship is "culturally reckoned and socially important" (Keesing, 1975, p. 24). Furthermore, kinship reckoning is always bilateral - that is, all societies recognize relationships on both "sides" (Keesing, 1975, pp. 22-23; see discussion below). Relatives on the mother's side are matrilateral (also maternal; Parkin, 1997, p. 36). Relatives on the father's side 
are patrilateral (also paternal; Parkin, 1997, p. 36).

Some societies also reckon descent, meaning that they attach social and cultural significance to subsets of these relationships, based on links of relatedness among people descended from an ancestral individual in a particular way. Effectively, the reckoning of descent emphasizes a "chain" of parent-child links between the ancestral individual and their descendants, and this sequence is socially and culturally salient (Keesing, 1975, pp. 17-18, 22, 148; Parkin, 1997, pp. 15-17).

Where the emphasis is restricted to either the mother's line or the father's line, descent is said to be unilineal. Specifically, it is termed matrilineal (also uterine; Parkin, 1997, p. 15) if traced along the matriline - from ancestral individual to descendants via a series of female links, i.e. from mother to daughter to daughter's daughter, etc. Conversely, it is termed patrilineal (also agnatic; Parkin, 1997, p. 15) if traced along the patriline - from ancestral individual to descendants via a series of male links, i.e. from father to son to son's son, etc.

Where the emphasis applies to all descendants of an ancestral individual through both female and male links, or through some combination of these, descent is said to be cognatic (also ambilateral, ambilineal, bilateral, non-unilineal; Parkin, 1997, p. 17; see discussion below). This is distinct from the co-occurrence of both types of unilineal descent, termed bilineal (also double or double unilineal; Keesing, 1975, pp. 73-75; Parkin, 1997, pp. 23-24). Note that the parental line through which descent is traced need not match the gender of the ancestral individual. For example, patrilineal descent may be traced back to an ancestress (Parkin, 1997, p. 19).

A society is said to have a rule of descent if a person's descent status determines membership in a socially or culturally defined category. In particular, a descent group is a kin group whose members share appropriate status, as specified by the society's descent rule (Keesing, 1975, p. 148; see discussion below). This does not imply that the individuals belonging to such a group reside together - indeed, they may never even meet as a group. In fact, the reckoning of descent need not lead to the formation of descent groups (Parkin, 1997, p. 17). These tend to be found where there is group property to manage (e.g. joint ownership of impartible land) or some group obligation to fulfil (e.g. worship of ancestral individuals) (Fox, 1983, p. 52).

To summarize, some societies recognize one or more modes of descent; in others, descent is only minimally salient, or not at all. Unlike kinship reckoning, then, descent reckoning is not universal 
(Keesing, 1975, pp. 21-22). Quoting Keesing (1975, p. 22),

"[i]n societies where descent groupings are culturally relevant, bilateral kinship is also always recognized and always important. Kinship reckoning creates a network of relationships between a great many individuals. A rule of descent gives special meaning to a limited subset of these relationships; it thus carves out pieces of this network and gives them some special social significance."

The analytical distinction between kinship and descent is tied to major theoretical developments that occurred in anthropology over the course of the twentieth century (see Holy, 1996, ch. 4, Kuper, 1982, and Parkin, 1997, ch. 12, for related discussion). In part, the terminological confusion lamented by Fox (1983, pp. 49-50), noted in Section 1, likely reflects divergent positions linked to these developments. A case in point is the multitude of terms used for different modes of descent, only a subset of which is given above! Another example relates to the terms used to designate descent groups. Generally, members of a descent group are said to form a lineage and, in some cases, a clan. The term "lineage" is used when the links among members are known and traceable to an actual ancestral individual, implying that the sequence of parent-child links from this person to their descendants is relatively shallow. Deeper sequences are not always recognized. Where they are, they may be traced back to a long-deceased ancestral individual (or even to a mythical entity, which need not be human), with links among members assumed, rather than known. The term "clan" is used to designate the group at this level. It follows that a clan may comprise multiple lineages (Fox, 1983, pp. 49-50; Keesing, 1975, pp. 148, 150; Parkin, 1997, pp. 17-18).

A potential point of confusion is that some authors reserve the two terms for unilineal descent groups, distinguishing between matrilineages/matriclans, if the descent rule is matrilineal, and patrilineages/patriclans, if the descent rule is patrilineal (e.g. Keesing, 1975, pp. 148, 150; Parkin, 1997, pp. 17-18). Other authors eschew the reference to unilineality, adding cognatic lineages/clans to the mix (e.g. Fox, 1983, pp. 49-50). A historical account of the theoretical developments underlying such variation in terminology is beyond the scope of my contribution, and of the theme issue more generally. At the same time, highlighting that variation exists may aid interpretation of relevant ethnographic materials, and of related discussions in anthropology more broadly (Parkin, 
1997, p. 18).

For completeness, then, note that the terms "bilateral" and "cognatic" are sometimes used interchangeably, as we saw above in the context of descent - that is, "cognatic descent", as defined above, can also be referred to as "bilateral descent" (Parkin, 1997, p. 17). Similarly, "bilateral kinship", as defined above, can also be referred to as "cognatic kinship" (Keesing, 1975, pp. 147, 148). The latter usage reflects the distinction between relatives by blood, collectively termed cognates, and relatives by marriage, collectively termed affines (Parkin, 1997, p. 35). To complicate matters, however, "bilateral descent" has also been used to indicate the absence of a rule of descent, with relatives aggregated only by blood and/or by marriage (e.g. Murdock and Wilson, 1972; see Section 4.1).

\section{Lineal kinship in cross-specific perspective}

A number of principles stem from the distinction between lateral and lineal kinship introduced in Section 2. Phrased in abstract terms, these apply generally to any animal species with biparental sexual reproduction. My aim here is to highlight the logical implications of relevant definitions given in Section 2; I demonstrate the analytic utility of the definitions in Section 4. For clarity, I focus on the matrilineal case; the patrilineal case is simply reversed.

We saw in Section 2 that relatives on the mother's side are matrilateral kin. A subset of these are matrilineal kin — namely, those related through the mother's line. It follows that matrilineal kin of either sex are related through females only. Males are included, but individuals related through males are not. Thus, the relationship between males who are related matrilineally is mediated by females. More broadly, if we were to trace out the relationships between any two individuals who are matrilineal kin, all the connecting links would be females (Fox, 1983, pp. 41-44).

Membership in a set of matrilineally related kin is gained through the mother, and the relationships between any two members of the set involves one or more female links. Membership applies to individuals of either sex, but it is restricted to the offspring of the females in the set. That is, membership passes from the females in the set onto their female and male offspring, and then, in turn, from the female offspring onto theirs, and so on. Assuming that the male offspring mate with 
females belonging to other sets of matrilineally related kin, their offspring will gain membership in those sets instead (Fox, 1983, pp. 41-44).

A key implication here is that matrilineal kinship delimits discrete, non-overlapping sets of individuals. Individuals belong to only one set of matrilineally related kin, as determined at birth. An individual's status in relation to any such set is absolute and exclusive - they either belong to the set or not, and membership in one set precludes membership in another. Of course, they belong simultaneously to a set of patrilineally related kin, with analogous properties. In and of itself, kinship does not partition populations into discrete, non-overlapping sets — rather, it connects individuals into a wider network of relationships (see Section 2). Status in this network is relative, not absolute, in the sense that, for example, one is an offspring with respect to a given individual, and a sibling with respect to another (Fox, 1983, pp. 46-49; Keesing, 1975, pp. 21-23).

Membership in sets of lineally related kin is often conflated with the lineal transmission of resources across generations (defined broadly to include the allocation of food, information, etc.). The underlying assumption is that a bias in membership towards one set over the other imposes a corresponding lineal bias in transmission. Generally, however, resources tend to cross the boundaries of any such set, extending to the wider kinship network, with different resources following different routes across generations (see Section 4). Therefore, the concepts of membership and transmission are best kept distinct (Fox, 1983, p. 52).

Take, for example, a hypothetical species in which females stay in the natal territory, whereas males disperse as juveniles. For simplicity, assume that populations in this species comprise adult females and their offspring, and that the two generations do not overlap - that is, reproduction begins in one generation only after it has ceased in the other. Adult females mate with unrelated adult males from other populations, interacting briefly and exclusively for this purpose, and adult males are solitary at all other times. Each mating pair produces one daughter and one son.

In this scenario, a population corresponds to a set of matrilineally related kin, comprising females of any age and pre-juvenile males. All of the properties outlined above relating to membership in such a set extend to the population as a whole. Additionally, individuals in the population interact only with matrilineal kin, to the exclusion of (i) any other kin - that is, other matrilateral kin (specifically, those related through males), their father, and any patrilateral kin, and (ii) any 
unrelated individuals, except their mate. This is because the population is effectively isolated from other populations, and thus from other sets of matrilineally related kin.

As a result, the properties relating to membership extend also to transmission. Say, for instance, that foraging skills are learnt from the mother. Thus, they pass from an adult female in the population onto both her offspring, then from her daughter onto hers, and so on. In each case, the son's offspring are born into another population (i.e. his mate's/their mother's), and they acquire foraging skills from their mother instead. In this scenario, then, all resources follow the matrilineal route within populations, and there is no transfer of resources between populations.

Now consider a slightly modified scenario, in which unrelated adult males join the population to mate with the adult females, and both parents are then involved in rearing of the offspring. Membership in the "resident" set of matrilineally related kin is as above, but transmission is not. Even if adult males are still solitary at all other times, biparental care and male dispersal, combined, add several routes for the transfer of resources across generations - both within and between populations. Within populations, resources can be transferred directly between females (from mother to daughter to daughter's daughter, etc.), and/or between males via females (from father to daughter to daughter's son, etc.). Between populations, resources can be transferred directly between males (from father to son to son's son, etc.), and/or between females via males (from mother to son to son's daughter, etc.).

Assuming that, in this scenario, foraging skills are learnt from both parents, they can follow multiple routes across generations - along either the mother's line or the father's line, or some combination of these. Other resources may be transferred predominantly, or exclusively, matrilineally. For instance, the pattern of female philopatry and male dispersal characteristic of the species implies that access to the natal territory follows this route, passing from mother to daughter to daughter's daughter, etc. (see Section 4.1).

To summarize, then, both scenarios feature a matrilineal bias in membership, resulting in the physical aggregation of matrilineally related kin. This bias maps onto a corresponding bias in transmission in the first scenario, but not in the second, reflecting other aspects of the social system. Crucially, in the second scenario different resources follow different routes across generations.

The example illustrates the distinction between the concepts of membership and transmission. 
Yet the two are implicitly conflated when we designate a kinship system — and, by extension, a whole species, or a population within it — as "matrilineal" or "patrilineal". For example, "matrilineal kinship" signals a bias towards matrilineally related kin. But is it a bias in membership, in transmission, or both? And does it apply to the transfer of all resources across generations, or do different resources follow different routes from one generation to another within and/or between populations?

Such lack of precision fuels the common misconception that it is not possible to define key terms and concepts unambiguously, and in a way that they apply across species (e.g. Mattison et al., 2019, and other articles in the theme issue). The example above and the preceding discussion show that this is clearly not the case. Framed as generically as they are, the two scenarios in the example provide plausible high-level descriptions for populations in a number of species — including our own.

This observation implies that the principles outlined above apply generally to any human society, irrespective of the degree of emphasis placed on descent from a common ancestor (see Section 2). That is, a lineal bias in membership and/or transmission may exist even in societies in which descent has only minimal social and cultural significance, or none. In these societies, any such bias is likely to involve closely related kin, and/or kin who interact on a regular basis. The reckoning of descent effectively extends the reach of the bias beyond this subset of kin. For example, shared descent status may be used to justify the transfer of resources between individuals who are only distantly related, do not reside together, and rarely interact.

It follows that the reckoning of descent is not intrinsic to lineal kinship organization in humans (see Section 4). This insight is at odds with current practice in anthropology, in which the terms "matriliny", "patriliny", and their derivatives (e.g. "matrilineal kinship", "patrilineal society") have come to indicate, more or less explicitly, matrilineal or patrilineal descent (e.g. Parkin, 1997, p. 15). The discrepancy generates considerable confusion, contributing to the misconception outlined above. By definition, descent reckoning involves the tracing of relationships beyond the subset of closely related kin, and/or kin who interact on a regular basis (see Section 2). Therefore, it relies on the combination of symbolic language and cumulative cultural transmission that uniquely characterizes much of human social behaviour. The scope to develop a cross-specific framework 
for the study lineal kinship organization appears limited as a result — a view that has historically prevailed in anthropology, persisting to this day (e.g. Parkin, 1997, pp. 3-8, 26-27, 137-138; see Cronk and Gerkey, 2007, for related discussion).

Resolving this impasse requires clarity in the definition of key terms and concepts - minimally, as I have done here, by separating out lateral and lineal kinship, a lineal bias in membership from a corresponding bias in transmission, and, specifically for humans, lineal kinship organization from the reckoning of descent (see Sections 2 and 4).

\section{Lineal kinship in cross-cultural perspective}

Ironically, the conflation of lineal kinship organization and descent reckoning, outlined in Section 3, is as problematic in anthropology as it is in cross-specific perspective. The need to distinguish between descent and other aspects of the social system has been long and widely recognized — from early writings on kinship in the nineteenth century (e.g. Tylor, 1889) through to recent specialist texts (e.g. Harrell, 1997, pp. 18-20; Parkin, 1997, pp. 21-26; see Schneider, 1961, pp. viii-x, for related discussion).

For instance, Tylor (1889, p. 258) emphasizes that "the maternal and paternal systems are not each a definite institution, but combinations in which more or less strictly the authority, descent, succession, inheritance follow the female or the male side." Writing over a century later, Parkin (1997, p. 23) notes that "it is rarely appropriate to characterize a whole society in terms of any particular mode of descent, for example, as 'patrilineal' or 'matrilineal' or 'cognatic', despite a widespread tendency to do so." At the same time, Harrell (1997, p. 19) suggests that such designations can be used as "a convenient shorthand" to describe a kinship system, with different labels capturing whether there is "a predominant route", or "an obvious mixture of routes", for the transmission of rights and duties across generations. This suggestion rests on the assumption that (Harrell, 1997, p. 18)

"[i]n practice, there is a strong tendency for certain directions of transmission of rights and duties (succession to office, descent, and inheritance) to be associated with corresponding systems of residence, so that those in line to inherit or succeed live with those 
they expect to inherit from or succeed to."

It should be clear from the discussion in Section 3 why such a suggestion is problematic at a conceptual level. For example, "matrilineal kinship" signals a bias towards matrilineally related kin, but it fails to specify (i) whether the bias applies to membership, to transmission, or both, and (ii) in the case of transmission, whether different resources follow different routes across generations. Furthermore, "matrilineal kinship" would likely be taken to imply matrilineal descent, because in current anthropological practice "matriliny" and derived terms have effectively come to indicate this specific aspect of the social system (e.g. Johnson, 2016). However, as discussed in Section 3, the reckoning of descent is not intrinsic to lineal kinship organization in humans - thus, a matrilineal bias in membership and/or transmission may exist even in societies that place no emphasis on descent from a common ancestor. Conceptually, then, the use of shorthand such as "matrilineal kinship" is imprecise and potentially misleading.

A related issue is that, at a practical level, any such designation is arbitrary. In particular, it is not clear what exact criteria must be met to establish that, in a given society, there is a predominant route for the transmission of rights and duties from one generation to another. In fact, the cross-cultural data reveal a complex pattern, challenging the underlying assumption that descent, succession, inheritance, and residence tend to feature a consistent bias - in this case, towards matrilineally related kin.

I give a concrete example below, focusing on the distribution of modes of descent and residence across societies (Section 4.1). Building on insights gleaned from this example, I then outline an approach to reframing lineal kinship organization in terms of biases in investment towards lineally related kin (Section 4.2).

\subsection{A cross-cultural example: the association between descent and residence}

The association between descent and residence has received considerable attention in anthropology (see Parkin, 1997, ch. 12, for related discussion). Investigation of the relationship between these aspects of the social system occupied the field in the late nineteenth century and for a good part of the twentieth. In particular, early debates focused on the relative primacy, or "priority", of 
different forms of social organization — both temporally (e.g. did "matriliny" precede "patriliny"?) and in terms of importance (i.e. do changes in descent drive changes in residence, or vice versa?). Within the prevailing theoretical paradigm of the late nineteenth century, now known as "classical evolutionism", the aim was to establish specific historical sequences, leading to the discovery of general laws of cultural development (see Fortunato, 2018, pp. 34-35, and Schneider, 1961, pp. viixi, for related discussion).

I do not intend to rehash these debates here. Rather, I turn to the cross-cultural data to evaluate the pervasive assumption of a "strong tendency" for descent to be associated with "corresponding systems of residence" (Harrell, 1997, p. 18). In the process I indulge in some technical detail about the data and underlying definitions, both for accurate interpretation and to illustrate the nuance required in drawing inferences from the ethnographic record. Finally, I introduce the notion that descent, residence, and other aspects of the social system represent pathways for the transmission of different resources across generations (see Section 4.2).

The cross-tabulation of relevant variables for the 186 societies in the Standard Cross-Cultural Sample (SCCS) (Murdock and White, 1969) is in Table 1 (modified from Table 2 in Murdock and Wilson, 1972, p. 274). Data for this sample provide the most accurate estimates of the distribution of cultural practices across human societies (e.g. compared to estimates based on equivalent data for its "parent" sample, the Ethnographic Atlas; Murdock, 1967a,b). The increase in accuracy derives from (i) specific considerations underlying the sampling strategy, (ii) explicit criteria for the inclusion of societies, based on the quality of the ethnographic materials, and (iii) refinement of the code definitions and corresponding data (see Fortunato, 2017, and Fortunato, 2018, p. 37, for related discussion).

For example, the code definitions for descent and residence were developed specifically for the $S C C S$ focusing on the community as "a unit of significant social interaction beyond the family" (Murdock and Wilson, 1972, p. 255). The corresponding data set the frequency of matrilineal descent in the SCCS at 14\% (Murdock and Wilson, 1972). An earlier estimate for this sample was based on code definitions originally developed for the Ethnographic Atlas, and the corresponding data set the frequency of matrilineal descent at 17\% instead (Murdock and White, 1969). The latter figure is more often cited (e.g. Holden et al., 2003), but it is likely less accurate than the 
former, for the reasons outlined above. Estimates of the frequency of different modes of descent and residence in the $S C C S$, based on the code definitions and corresponding data in Murdock and Wilson (1972), are included in Table 1.

The SCCS code for descent (data column 10 in Murdock and Wilson, 1972) maps onto the definitions in Section 2 relatively straightforwardly. The one exception is the "bilateral descent" category, which indicates "more properly the absence of any rule affiliating an individual with the kin group or groups of an ancestor" (Murdock and Wilson, 1972, p. 274; see Section 2). For clarity, this category is reported as "no rule" in Table 1.

The SCCS code for residence (data column 9 in Murdock and Wilson, 1972) presents some peculiarities compared to other definitions found in the literature. These peculiarities reflect the terminological and conceptual confusion that has historically characterized efforts to classify residence modes, persisting to this day (see Alvarez, 2004, pp. 421-423, Fortunato, 2011, and Schneider, 1961, pp. ix-xi, for related discussion). Here I highlight specific features of the $S C C S$ code relevant to interpretation of Table 1.

Focusing on the location of men and women after marriage, or post-marital residence, the simplest classification comprises neolocality, i.e. residence of the married couple apart from the kin of either spouse, uxorilocality, i.e. residence of the married couple with or near the wife's kin, and virilocality, i.e. residence of the married couple with or near the husband's kin (Keesing, 1975, p. 37). The latter two terms are "unobjectionable from both the etymological and logical points of view" (Adam, 1947, p. 678) - unlike their more commonly used counterparts, matrilocality and patrilocality (see Parkin, 1997, p. 31, for related discussion). The SCCS code gives both sets of terms as alternatives, but defined more narrowly as residence with or near, respectively, the wife's female matrilineal kin and the husband's male patrilineal kin.

In addition to neolocality, uxorilocality, and virilocality, the SCCS code includes ambilocality, defined as residence optionally with or near the parents of either spouse, depending on personal choice or circumstances, and avunculocality, defined as residence with or near the husband's mother's brother or other male matrilineal kin, including cases where men customarily marry a mother's brother's daughter and thus reside with wife's kin. Notable for its absence is duolocality, in which the spouses live apart (Parkin, 1997, p. 32) - effectively, the SCCS code assumes 
co-residence of the spouses.

To aid interpretation, following Harrell (1997, pp. 17-19) it is useful to view the different modes of residence as different routes for the transfer of access to the natal household across generations. The emphasis is on cooperation in activities relating to the family (e.g. sex, socialization, the procuring and processing of food and other material resources), rather than on physical proximity - a distinction that generally excludes other types of co-residence, such as lodging in shared accommodation. If a married couple is to live together and cooperate in these activities, one option is that both spouses leave the natal household to set up a separate place of residence. This scenario results in neolocality. The other option is that only one of the spouses leaves the natal household. This scenario results in the other modes listed above, depending on which spouse tends to retain access to the natal household. In cross-specific perspective, then, residence is analogous to the transfer of access to the natal territory across generations, as captured by the pattern of philopatry and dispersal (see Section 3).

Mapping this framework onto the $S C C S$ code (Murdock and Wilson, 1972), in neolocality there is no transfer of access to the natal household across generations (Harrell, 1997, p. 19). The transfer is matrilineal in avunculocality and uxorilocality - respectively, between matrilineally related males (i.e. from maternal brother to sororal nephew) and between matrilineally related females (e.g. from mother to daughter, if residence is with the wife's parents) (Harrell, 1997, p. 19). Similarly, the transfer is patrilineal in virilocality (e.g. from father to son, if residence is with the husband's parents). In ambilocality the transfer is matrilineal or patrilineal with approximately equal frequency (Murdock and Wilson, 1972).

Having established a framework for interpretation, we can finally turn to Table 1 and evaluate the assumption of association between matrilineal/patrilineal descent and matrilineal/patrilineal transfer of access to the natal household across generations (e.g. Harrell, 1997, p. 18). In line with the assumption, matrilineal descent occurs almost exclusively with avunculocal and uxorilocal residence (specifically, 25 of 26 societies with matrilineal descent, or 96\%). Similarly, patrilineal descent occurs almost exclusively with virilocal residence (specifically, 70 of 75 societies with patrilineal descent, or 93\%). The reverse does not hold quite as neatly, however. Notably, the majority of societies with no descent rule feature uxorilocal or virilocal residence (specifically, 50 of 68 soci- 
eties with no descent rule, or $74 \%$, focusing on entries with data for both variables). Thus, more often than not, societies that do not reckon descent present a clear bias towards lineally related kin in the transfer of access to the natal household across generations. For example, there are as many societies featuring uxorilocal residence with no descent rule, as there are societies featuring uxorilocal residence and matrilineal descent (for each combination, 18 of 38 societies with uxorilocal residence, or $47 \%)$.

To make sense of this pattern, it is useful to view different aspects of the social system as pathways for the transmission of different resources across generations (defined broadly to include the allocation of material wealth, such as land, livestock, and household goods; embodied wealth, such as practical skills and the determinants of physical condition; and relational wealth, such as position and links in social support networks; Borgerhoff Mulder et al., 2009). Thus, as discussed above, residence can be viewed as the transfer of access to the natal household. Similarly, descent can be viewed as the transfer of social ties. In the many "discrepant" cases in Table 1, these resources follow different routes from one generation to another, such that residence may present a bias towards one set of lineally related kin and descent towards the other set, or such that a lineal bias in residence may exist even in societies in which descent has no social and cultural significance. Overall, then, the pattern in Table 1 is consistent with key insights derived from first principles in Section 3.

The available cross-cultural data suggest that this pattern extends to other aspects the social system, including inheritance of property (e.g. Murdock, 1949, pp. 37-39) and succession to office (e.g. Aberle, 1961, pp. 707-708). It thus becomes clear that it is not at all straightforward to determine whether, in any society, there is a predominant route for the transmission of rights and duties across generations. This highlights the ambiguity involved in designating a kinship system — and, by extension, a whole society, or a population within it — as "matrilineal" or "patrilineal" (see Section 3). 
Table 1: Cross-tabulation of modes of descent and residence in the Standard Cross-Cultural Sample ${ }^{1}$

\begin{tabular}{|c|c|c|c|c|c|c|c|c|}
\hline & & \multicolumn{5}{|c|}{ descent $(n)^{2}$} & \multicolumn{2}{|c|}{ total } \\
\hline & & ambilineal & double & matrilineal & no rule & patrilineal & $n$ & $\%$ \\
\hline \multirow[t]{6}{*}{ residence $(n)^{3}$} & ambilocal & 0 & 0 & 0 & 11 & 1 & 12 & 6 \\
\hline & avunculocal & 0 & 1 & 7 & 0 & 0 & 8 & 4 \\
\hline & neolocal & 0 & 0 & 0 & 7 & 2 & 9 & 5 \\
\hline & uxorilocal & 0 & 0 & 18 & 18 & 2 & 38 & 21 \\
\hline & virilocal & 6 & 9 & 1 & 32 & 70 & 118 & 64 \\
\hline & NA & 0 & 0 & 0 & 1 & 0 & 1 & - \\
\hline \multirow[t]{2}{*}{ total } & $n$ & 6 & 10 & 26 & 69 & 75 & 186 & \\
\hline & $\%$ & 3 & 5 & 14 & 37 & 40 & & \\
\hline
\end{tabular}

${ }^{1}$ Modified from Table 2 in Murdock and Wilson (1972, p. 274). Minor discrepancies between the percentages reported here and in Murdock and Wilson (1972) arise from inconsistency in the rounding of figures in the latter.

${ }^{2}$ The corresponding variable is data column 10 in Murdock and Wilson (1972, pp. 261-262). I changed "bilateral descent" in the original to "no rule"; see text for details.

${ }^{3}$ The corresponding variable is data column 9 in Murdock and Wilson (1972, p. 261), focusing here on "the prevailing practice of residence after marriage" (i.e. excluding information on "an alternative but less frequent residential pattern or one confined to a particular phase of the developmental cycle"). I changed "matrilocal" in the original to "uxorilocal", and "patrilocal" to "virilocal"; see text for details. One society (Botocudo, \#178) lacks data for this variable; percentages in the right-most column relate to the remaining 185 societies. 


\subsection{Reframing lineal kinship organization as lineal biases in kin investment}

The conceptual confusion underlying the ambiguity in terminology highlighted in Section 4.1 was first recognized in anthropology in the first half of the twentieth century (e.g. Lowie, 1919; Lowie, 1920, pp. 170-174; Murdock, 1937, pp. 458-459; Murdock, 1949, pp. 37-39; Rivers, 1924, ch. 5). Separation of the different aspects of the social system which may feature a bias towards lineally related kin represented a major advance in the study of matrilineal kinship (see Schneider, 1961, pp. vii-xii, for related discussion). Indeed, the notion was considered received wisdom by the middle of the century, with Richards (1950, p. 207) stating, for example, that

"[...] it is generally recognized that no society is entirely matrilineal or patrilineal as regards descent, inheritance, succession, and authority, but that the family system provides a balance of interests and rights between the two sides of the family with a predominant emphasis on one side or the other [...]."

Divergent theoretical positions elaborated over the course of the century emphasized this notion to different degrees, however (see Holy, 1996, ch. 4, Kuper, 1982, and Parkin, 1997, ch. 12, for related discussion). In any case, it appears to have been largely lost in current practice - likely in the transition that began around the 1970s when, as noted in Section 1, matriliny, and kinship more generally, were displaced from the core of anthropological enquiry, at the same time as researchers from other fields turned their attention to the topic. The recent introduction of biologically inspired labels, such as "female-biased/based/centred kinship", is symptomatic of the latter development. These labels are no less ambiguous than those they are intended to replace, with conceptual and practical issues analogous to those outlined above with reference to the use of "matrilineal kinship" as shorthand. Additionally, labels such as "female-biased/based/centred kinship" gloss over the distinction between lateral and lineal kin (see Sections 2 and 3). This is a potentially fatal oversight for explanations that rely on specific assumptions about relatedness in determining the relative costs and benefits of different strategies (see Fortunato, 2012, and Rogers, 2013, for discussion of relevant assumptions in the case of matrilineal inheritance).

The solution I propose here effectively recapitulates the earlier notion, reframing it in terms of biases in investment towards lineally related kin. In this context, the term "investment" simply 
indicates the transfer of resources to one or more individuals, to the exclusion of other individuals. It does not imply that the transfer is driven by personal choice, rather than by adherence to a social norm - that is, there is no implicit statement about agency (see Smith, 2013, for related discussion).

Building on the premise that "no society is entirely matrilineal" (Richards, 1950, p. 207), in Fortunato (2012) I define matrilineal kinship organization as a social system that emphasizes interactions among matrilineally related kin, and thus individuals related through females only (see Sections 2 and 3). In a given society, the emphasis may be expressed in one or more social domains, including descent reckoning, inheritance of property, succession to office, post-marital residence, and authority within the family (Rivers, 1924, pp. 85-90). In each domain, matrilineal kinship may serve as one of the criteria used to allocate rights and duties among individuals. Other relevant criteria are age and gender, for example.

By extension, here I define lineal kinship organization as a social system that emphasizes interactions among lineally related kin (see Sections 2 and 3). In a given society, the emphasis may be towards matrilineal kin in some social domains, and towards patrilineal kin in others; other domains still may present no such emphasis. A lineal bias in any domain can be viewed as a bias in investment towards a particular set of kin — specifically, towards the children of daughters if the bias is matrilineal, and towards the children of sons if the bias is patrilineal. Effectively, investment is restricted to the children of the "women of the group" (Fox, 1983, p. 42) in one case, and to the children of the "men of the group" (Fox, 1983, p. 42) in the other (Fox, 1983, pp. 41-46). Crucially, this is distinct from a bias in investment towards daughters and towards sons, respectively. For example, in the matrilineal case investment may be restricted to the sons of the women, to the exclusion of the women's daughters. A clear illustration is the transfer of property from a man to his sororal nephew, in which resources flow between matrilineally related males (i.e. between males via females). This form of matrilineal inheritance, termed mother's brother-sister's son inheritance, is distinct from the transfer of property from mother to daughter, in which resources flow between matrilineally related females (i.e. directly between females). The distinction highlights the confusion that may arise from framing matriliny as daughter-biased investment (Holden et al., 2003; Mattison, 2011). 
Viewing different aspects of the social system as pathways for the transmission of different resources across generations, as suggested in Section 4.1, it follows that the relative costs and benefits of investment in matrilineal vs. patrilineal kin may vary across social domains. For example, the costs and benefits to a man of investing in sister's vs. wife's offspring may differ for material, embodied, and relational wealth. In fact, they may differ also for different forms of wealth of the same type, such as land and livestock (Fortunato, 2012).

Conceptually, a key implication is that explanations for biases towards lineally related kin must not be confounded across social domains. Clearly, the factors leading to a bias towards a particular set of kin in one domain may have analogous effects in others, and there will likely be feedback across domains. For example, a bias towards matrilineal kin in assigning group membership may favour the physical aggregation of matrilineally related women and their dependants, and/or vice versa. At the same time, there is no reason to assume that the factors leading to matrilineal descent will inevitably result in matrilineal transfer of access to the natal household (see Fox, 1983, pp. 95-96, for related discussion).

The approach to defining lineal kinship organization I propose here is consistent with the crosscultural pattern examined in Section 4.1. Furthermore, it resolves the ambiguity implicit in current usage of "matriliny", "patriliny", and derived terms (e.g. "matrilineal kinship", "patrilineal society"), as well as biologically inspired labels (e.g. "female-biased/based/centred kinship"), by separating out lateral and lineal kinship, a lineal bias in membership from a corresponding bias in transmission, and lineal kinship organization from the reckoning of descent (see Sections 2 and 3). In particular, it corroborates the insight that descent reckoning is not intrinsic to lineal kinship organization in humans - rather, it is only one of many social domains in which an emphasis towards lineally related kin may be expressed in a given society.

\section{Conclusion}

I conclude by briefly outlining how the framework introduced in Section 4.2 applies in cross-specific perspective. To this end, I simply reiterate the key relevant points, eschewing references to features of social organization that are exclusive to humans (e.g. descent reckoning, post-marital residence). 
Lineal kinship organization is a social system that emphasizes interactions among lineally related kin - that is, individuals related through females only, if the emphasis is towards matrilineal kin, and individuals related through males only, if the emphasis is towards patrilineal kin (see Section 3). In a given population, the emphasis may be expressed in one or more social domains, corresponding to pathways for the transmission of different resources across generations (e.g. the allocation of food, information, and so on, or the transfer of access to the natal territory). The relative costs and benefits of investment in matrilineal vs. patrilineal kin may vary for different resources, leading to an emphasis towards matrilineal kin in some domains and towards patrilineal kin in others, with other domains still presenting no such emphasis.

A lineal bias in any domain can be viewed as a bias in investment towards a particular set of kin - specifically, towards the offspring of daughters if the bias is matrilineal, and towards the offspring of sons if the bias is patrilineal. Thus, investment is directed to the offspring of the females in the population in one case, and to the offspring of the males in the other. This is distinct from a bias in investment towards daughters and towards sons, respectively. For example, in the matrilineal case investment may be restricted to the sons of the females in the population, to the exclusion of the females' daughters. Resources are transferred matrilineally in both scenarios, but they flow between males via females in the first, and directly between females in the second (see Section 3).

Across species, then, it is important to specify which social domains the bias applies to, if any (e.g. the allocation of food or the transfer of access to the natal territory), and the precise route different resources follow across generations (e.g. between males via females or directly between females). More broadly, explanations for biases towards lineally related kin must not be confounded across domains. Of course, the same factors may lead to a bias towards a particular set of kin in more than one domain, and feedback across domains seems likely. For example, the physical aggregation of matrilineally related females and their dependants may facilitate the transfer of, say, foraging skills from mother to offspring. Similarly, the transfer of foraging skills from mother to offspring may favour the physical aggregation of matrilineally related females and their dependants. However, there is no reason to assume that the same factors are at play in the two domains, nor that a bias towards matrilineally related females in one domain will inevitably lead to a corresponding bias in the other (see Section 3). 
The overall implication is that viewing matriliny and patriliny as unitary phenomena may hinder understanding of variation in social behaviour within and across species. In particular, the underlying variation is masked by the common practice of designating a species, a population, or a kinship system as "matrilineal" or "patrilineal". Recourse to alternative labels such as "femalebiased kinship" does not address this issue. Rather, what is required is precision in the definition of key terms and concepts, with separation of the different aspects of the social system which may feature a bias towards lineally related kin.

Acknowledgements I thank Monique Borgerhoff Mulder, Shakti Lamba, and Robert Parkin for feedback on the manuscript, and Mary Shenk and two anonymous referees for input in the review process.

\section{References}

Aberle, D. F. (1961). Matrilineal descent in cross-cultural perspective. In Schneider and Gough (1961), chapter 17, pages 655-727.

Adam, L. (1947). Virilocal and uxorilocal. American Anthropologist, 49(4):678.

Alexander, R. D. (1974). The evolution of social behavior. Annual Review of Ecology and Systematics, 5:325-383.

Alexander, R. D. (1977). Natural selection and the analysis of human sociality. In Goulden, C. E., editor, Changing scenes in the natural sciences, 1776-1976, pages 283-337. Academy of Natural Sciences, Philadelphia, PA.

Alvarez, H. P. (2004). Residence groups among hunter-gatherers: a view of the claims and evidence for patrilocal bands. In Chapais, B. and Berman, C. M., editors, Kinship and behavior in primates, chapter 18, pages 420-442. Oxford University Press, New York, NY.

Bachofen, J. J. (1861). Das Mutterrecht: eine Untersuchung über die Gynaikokratie der alten Welt nach ihrer religiösen und rechtlichen Natur. Krais \& Hoffmann, Stuttgart. 
Borgerhoff Mulder, M., Bowles, S., Hertz, T., Bell, A., Beise, J., Clark, G., Fazzio, I., Gurven, M., Hill, K., Hooper, P. L., Irons, W., Kaplan, H., Leonetti, D., Low, B., Marlowe, F., McElreath, R., Naidu, S., Nolin, D., Piraino, P., Quinlan, R., Schniter, E., Sear, R., Shenk, M., Smith, E. A., von Rueden, C., and Wiessner, P. (2009). Intergenerational wealth transmission and the dynamics of inequality in small-scale societies. Science, 326(5953):682-688.

Cronk, L. and Gerkey, D. (2007). Kinship and descent. In Dunbar, R. I. M. and Barrett, L., editors, Oxford handbook of evolutionary psychology, chapter 31, pages 463-478. Oxford University Press, Oxford.

Douglas, M. (1969). Is matriliny doomed in Africa? In Douglas, M. and Kaberry, P. M., editors, Man in Africa, pages 121-135. Tavistock Publications, London.

Flinn, M. (1981). Uterine vs. agnatic kinship variability and associated cousin marriage preferences: an evolutionary biological analysis. In Alexander, R. D. and Tinkle, D. W., editors, Natural selection and social behavior: recent research and new theory, chapter 26, pages 439-475. Chiron Press, New York, NY.

Fortunato, L. (2011). Reconstructing the history of residence strategies in Indo-European-speaking societies: neo-, uxori-, and virilocality. Human Biology, 83(1):107-128.

Fortunato, L. (2012). The evolution of matrilineal kinship organization. Proceedings of the Royal Society B: Biological Sciences, 279(1749):4939-4945.

Fortunato, L. (2017). Insights from evolutionary anthropology on the (pre)history of the nuclear family. Cross-Cultural Research, 51(2):92-116.

Fortunato, L. (2018). Systematic comparative approaches to the archaeological record. In Sabloff, J. A. and Sabloff, P. L. W., editors, The emergence of pre-modern states: new perspectives on the development of complex societies, chapter 3, pages 33-49. SFI Press, Santa Fe, NM.

Fox, R. (1983). Kinship and marriage: an anthropological perspective. Cambridge University Press, New York, NY. Originally published by Penguin Books Ltd, 1967; reissued with a new Preface. 
Gaulin, S. J. C. and Schlegel, A. (1980). Paternal confidence and paternal investment: a cross cultural test of a sociobiological hypothesis. Ethology and Sociobiology, 1(4):301-309.

Gray, J. P. and Wolfe, L. D. (1982). A note on brother inheritance. Ethology and Sociobiology, $3(2): 103-105$.

Greene, P. J. (1978). Promiscuity, paternity, and culture. American Ethnologist, 5(1):151-159.

Harrell, S. (1997). Human families. Westview Press, Boulder, CO.

Hartung, J. (1981). Paternity and inheritance of wealth. Nature, 291(5817):652-654.

Hartung, J. (1982). Comment: reply to Gray and Wolfe. Ethology and Sociobiology, 3(2):101.

Hartung, J. (1985). Matrilineal inheritance: new theory and analysis. Behavioral and Brain Sciences, 8(4):661-670.

Holden, C. J., Sear, R., and Mace, R. (2003). Matriliny as daughter-biased investment. Evolution and Human Behavior, 24(2):99-112.

Holy, L. (1996). Anthropological perspectives on kinship. Pluto Press, London.

Johnson, J. (2016). Matriliny. In Stein, F., Lazar, S., Candea, M., Diemberger, H., Robbins, J., Sanchez, A., and Stasch, R., editors, The Cambridge Encyclopedia of Anthropology. Retrieved on 2019-01-20 from http://doi.org/10.29164/16matriliny.

Keesing, R. M. (1975). Kin groups and social structure. Holt, Rinehart and Winston, New York, NY.

Kuper, A. (1982). Lineage theory: a critical retrospect. Annual Review of Anthropology, 11(1):7195.

Kurland, J. A. (1979). Paternity, mother's brother, and human sociality. In Chagnon, N. A. and Irons, W., editors, Evolutionary biology and human social behavior: an anthropological perspective, chapter 6, pages 145-180. Duxbury Press, North Scituate, MA. 
Lowie, R. H. (1919). The matrilineal complex. University of California Publications in American Archaeology and Ethnology, 16(2):29-45.

Lowie, R. H. (1920). Primitive society. Boni and Liveright, New York, NY.

Mattison, S. (2011). Evolutionary contributions to solving the "matrilineal puzzle": a test of Holden, Sear, and Mace's model. Human Nature, 22(1-2):64-88.

Mattison, S. M., Shenk, M. K., Emery Thompson, M., Borgerhoff Mulder, M., and Fortunato, L. (2019). The evolution of female-biased kinship in humans and other mammals. Philosophical Transactions of the Royal Society B: Biological Sciences, 374(1780):20190007.

Murdock, G. P. (1937). Correlations of matrilineal and patrilineal institutions. In Murdock, G. P., editor, Studies in the science of society, pages 445-470. Yale University Press, New Haven, CT.

Murdock, G. P. (1949). Social structure. The Free Press, New York, NY.

Murdock, G. P. (1967a). Ethnographic Atlas. University of Pittsburgh Press, Pittsburgh, PA.

Murdock, G. P. (1967b). Ethnographic Atlas: a summary. Ethnology, 6(2):109-236.

Murdock, G. P. and White, D. R. (1969). Standard cross-cultural sample. Ethnology, 8(4):329-369.

Murdock, G. P. and Wilson, S. F. (1972). Settlement patterns and community organization: crosscultural codes 3. Ethnology, 11(3):254-295.

Parkin, R. (1997). Kinship: an introduction to basic concepts. Blackwell Publishers Ltd, Oxford.

Peters, P. E. (1997). Introduction. Critique of Anthropology, 17(2):125-146.

Richards, A. I. (1950). Some types of family structures amongst the Central Bantu: characteristics of matrilineal kinship organizations in Central Africa. In Radcliffe-Brown, A. R. and Forde, D., editors, African systems of kinship and marriage, pages 207-251. Oxford University Press for the International African Institute, London.

Rivers, W. H. R. (1924). Social organization. Kegan Paul, Trench, Trubner \& Co., Ltd., London. 
Rogers, A. R. (2013). Genetic relatedness to sisters' children has been underestimated. Proceedings of the Royal Society B: Biological Sciences, 280(1751):20121937.

Schneider, D. M. (1961). Preface. In Schneider and Gough (1961), pages vii-xvii.

Schneider, D. M. and Gough, K., editors (1961). Matrilineal kinship. University of California Press, Berkeley, CA.

Smith, E. A. (2013). Agency and adaptation: new directions in evolutionary anthropology. Annual Review of Anthropology, 42(1):103-120.

Tylor, E. B. (1889). On a method of investigating the development of institutions; applied to laws of marriage and descent. The Journal of the Anthropological Institute of Great Britain and Ireland, 18:245-272.

Wolfe, L. D. and Gray, J. P. (1981). Comment on Gaulin and Schlegel (1980). Ethology and Sociobiology, 2(2):95-98. 